\title{
A technique for the investigation of intracranial pressure in man
}

\author{
A. HULME AND RAY COOPER \\ From the Department of Neurosurgery, Frenchay Hospital, Bristol, and Burden \\ Neurological Institute, Stapleton, Bristol
}

Measurements of intracranial pressure have an important place in the investigation of neurological disease. Isolated estimations provide limited information, but more precise and valuable data are obtained by monitoring intracranial pressure changes over an extended period.

A number of workers have published reports describing graphic methods for recording lumbar or ventricular fluid pressures (Blackfan, Crothers, and Ganz, 1929; Carmichael, Doupe, and Williams, 1937; Antoni, 1946; Ryder, Espey, Kristoff, and Evans, 1951; Guillaume and Janny, 1951; Lundberg, 1960; Keegan and Evans, 1962; and others). Lundberg (1960) in his monograph 'Continuous recording and control of ventricular fluid pressure in neurosurgical practice' has published detailed recordings of ventricular fluid pressure changes in a large series of patients and has drawn attention to the characteristic pressure waves which are observed.

Most of the techniques described rely upon the measurement of cerebrospinal fluid pressure in the lumbar sac or a lateral ventricle by means of a tube connected to a pressure transducer or manometer (Lundberg and others). Success requires satisfactory placement of the tube in the fluid space and maintenance of unobstructed communication with the recording apparatus. Lundberg mentions that the ventricular catheter became blocked in 17 of his cases with consequent interruption of recordings. Other workers have used small fluid-filled latex tambours inserted into the subdural space and connected by means of a tube to a pressure transducer and recorder (Hoppenstein, 1965).

In our investigation we considered it essential that the following criteria should be fulfilled:-1 The method must be simple, reliable, and able to function efficiently under a wide variety of conditions for prolonged periods, either continuously or intermittently with only occasional expert supervision. 2 It must cause no significant additional discomfort or risk to the patient. 3 It must be simple to disconnect the patient from the recording apparatus so as to impose no unnecessary restriction of activities or interference with other investigations or treatment. 4 It must yield the maximum information concerning variations in intracranial pressure and other relevant phenomena.

In the technique described below a pressuresensitive transducer is inserted directly into the skull.

The advantages of the method are. 1 It is not dependent on cerebrospinal fluid drainage, and the technical difficulties of maintaining a free fluid communication, particularly when the ventricles are small or distorted, are avoided. 2 The transducer can be inserted at any convenient place in the skull and will record the pressure exerted by the brain against the cranium at that point (Fig. 1). 3 The risk of infection is minimal. Experience in the treatment of psychiatric disorders by multifocal leucotomy has shown that multiple intracerebral gold electrodes may be left in situ for many months? without significant hazard (Crow, Cooper, and Phillips, 1961). The leads from the transducer emerging through the scalp wound are much finer than a ventricular catheter (not more than $1 \mathrm{~mm}$. in diameter) and we have encountered no case of sepsis. Ps. pyocyanea was cultured from one wound swab on removal of the transducer after four and a half weeks, but the wound healed soundly without clinical evidence of infection. 4 The insertion of the pressure transducer is conveniently combined with the placement of subdural gold electrodes for monitoring phenomena such as cortical E.E.G., oxygen availability, and electrical impedance. 5 At the conclusion of recording the transducer can be removed very easily under local anaesthesia and after sterilization is available for further use. In practice the method is well tolerated, and patients have admitted no discomfort.

\section{METHOD}

The early investigations were carried out using pressure transducers constructed by R. Pacifico of the Sound \& 
A.

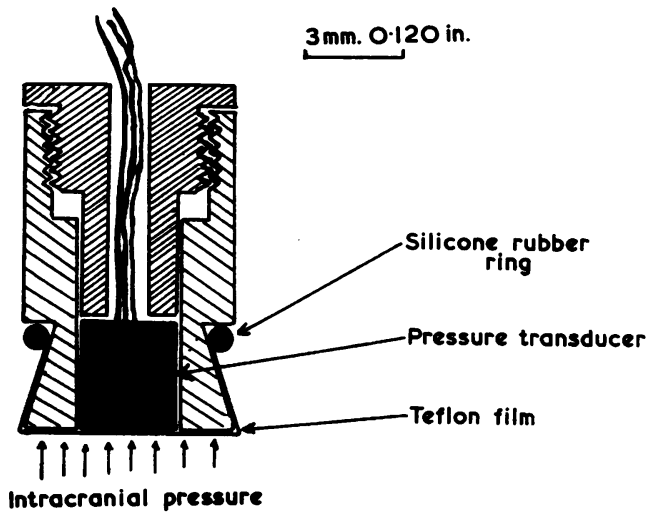

FIG. 1a. The pressure transducer in the stainless steel housing.
B.

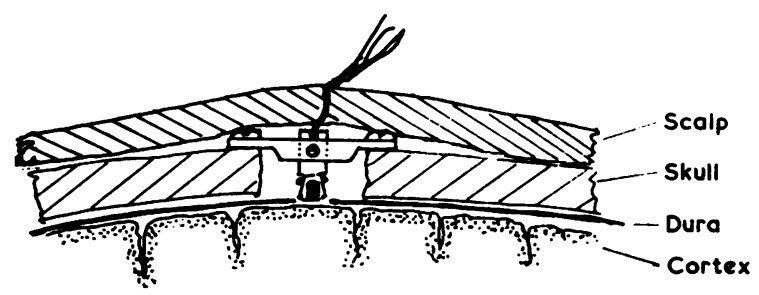

Vibration Research Institute, University of Southampton. These transducers were satisfactory for measurement of changes of intracranial pressure taking place over several hours but because of long-term instability of the base line they were not suitable for measurement of mean pressure over a period of days or weeks. The type of pressure transducer presently used is manufactured by Schaevitz-Bytrex Corporation, Waltham, Mass., U.S.A., and is known as the HFD 2. This is a very small transducer only 0.125 in. $(3 \mathrm{~mm}$.) diameter and the sensitivity and base line are stable over prolonged periods. The standard HFD 2 pressure transducer is not designed for biological work and the recommended excitation voltage has been reduced by a factor 10 so that the temperature rise of the transducer, which is normally quite high, is negligible. The output of the transducer under these conditions is about $250 \mu \mathrm{V}$ for $500 \mathrm{~mm}$. $\mathrm{H}_{2} \mathrm{O}$ change in pressure.

In use the pressure transducer is contained in a stainless steel sleeve fastened in a stainless steel strap spanning the burr hole. The open end of the sleeve is closed by Teflon film (12 $\mu, 0.0005$ in. thick) which prevents the nickelplated brass diaphragm from touching the cortex (Fig. 1a). The position of the sleeve in the strap is adjusted so that the protected diaphragm of the transducer is in contact with the cortex level with the inner surface of the dura. The wires are brought out through the scalp (Fig. $1 b)$, together with a narrow bore $(0.5 \mathrm{~mm} .0 .020$ in. diameter) silicone rubber tube open to the atmosphere which provides the reference pressure to the transducer. In this

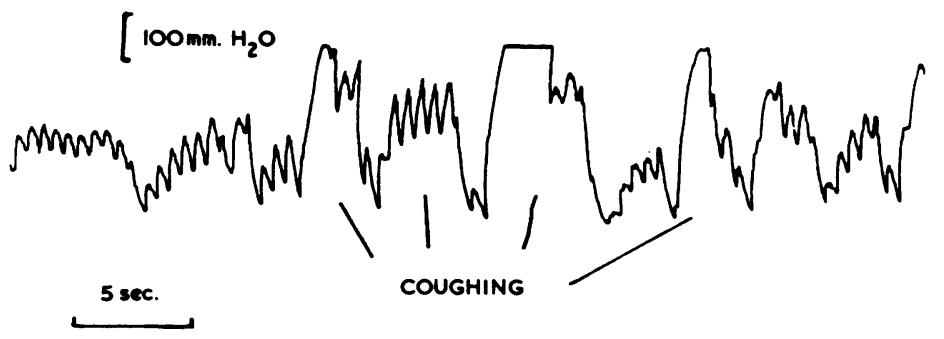

FIG. 2. Changes of pressure caused by coughing (upper trace) and jugular pressure (lower trace). The changes in intracranial pressure by coughing were about $400 \mathrm{~mm} . \mathrm{H}_{2} \mathrm{O}$.

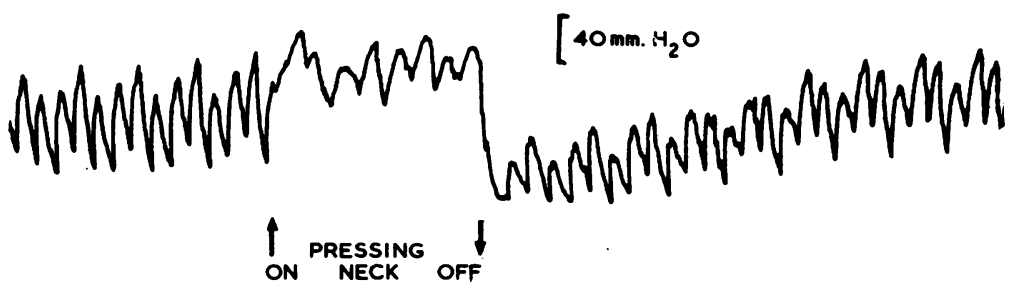




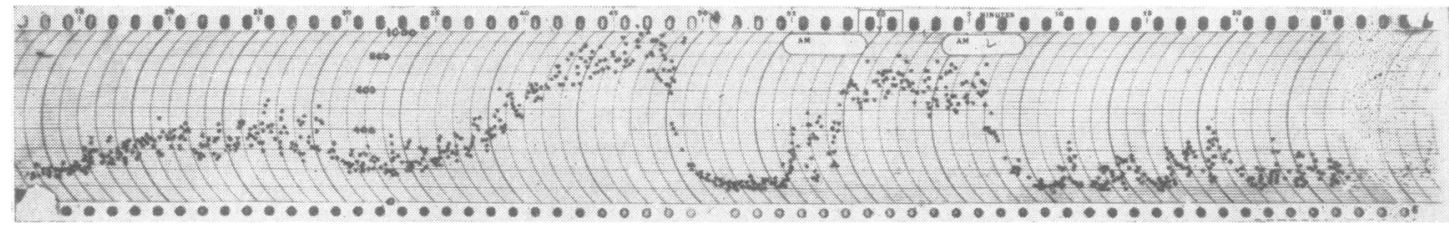

FIG. 3. Recording of intracranial pressure for one and a half hours taken during sleep. Full-scale deflection 1,000 $\mathrm{mm}$.

$\mathrm{H}_{2} \mathrm{O}$. The recorder marks the pressure every five seconds. The scatter on the recording is due to the cardiac pulsations (larger at higher values of intracranial pressure). The record shows two pressure waves each lasting 12 minutes. The peak pressure during the first wave was $1,000 \mathrm{~mm} . \mathrm{H}_{2} \mathrm{O}$.

way the intracranial pressure is measured with respect to atmospheric pressure.

When not in use the pressure transducer is removed from the sleeve and stored in formalin vapour. Further sterilization is carried out just before use by immersion in $0.5 \%$ hibitane in $70 \%$ spirit for one hour. The stainless steel sleeving and Teflon film are sterilized by boiling.

The intracranial pressure is measured using a DC amplifier and a slow speed recorder which marks the pressure every five seconds. When additional physiological variables are being recorded an Offner type $T$ dynograph is used.

\section{COMMENT}

To date recordings have been made in 13 patients in whom it was necessary to make burr holes for diagnosis or treatment, and our observations are largely confined to cases with evidence of raised intracranial pressure.

We have been impressed by the lability and wide range of variation of intracranial pressure and the rapidity with which it is affected by other factors, especially respiratory and vascular (Fig. 2). Of particular interest and significance are the large pressure waves which have been observed in patients with a high mean level of intracranial pressure (Fig. 3).

Detailed results will be reported elsewhere.

\section{SUMMARY}

A technique is described for measurement of intracranial pressure in man using a small pressure transducer implanted in the skull. The method presents advantages, especially for long-term recordings, since it is not dependent on communication with cerebrospinal fluid pathways.

Use of the slow speed recorder enables nurses and doctors to observe changes of intracranial pressure and may give warning of an ominous increase before clinical signs are observed.

The authors wish to express their appreciation for the assistance given by the Research Grants Committees of the United Bristol Hospitals and the South Western Regional Hospital Board and the W. Clement and Jessie V. Stone Foundation.

\section{REFERENCES}

Antoni, N. (1946). Pressure curves from the cerebrospinal fluid Acta med. scand., suppl., 170, pp. 439-462.

Blackfan, K. D., Crothers, B., and Ganz, R. N. (1929). Transmission of intracranial pressure in hydrocephalus in infancy. Amer J. Dis. Child., 37, 893-899.

Carmichael, E. A., Doupe, J., and Williams, D. J. (1937). The cerebrospinal fluid pressure of man in the erect posture. J. Physiol. (Lond.), 91, 186-201.

Crow, H. J., Cooper, R., and Phillips, D. G. (1961). Controlled multifocal frontal leucotomy for psychiatric illness. J. Neurol. Neurosurg. Psychiat., 24, 353-360.

Guillaume, J., and Janny, P. (1951). Mamométrie intracranienne continue. Rev. neurol., 84, 131-142.

Hoppenstein, R. (1965). A device for measuring intracranial pressure. Lancet, $1,90$.

Keegan, H. R., and Evans, J. P. (1962). Studies of cerebral swelling, III. Long term recordings of cerebrospinal fluid pressure before and following parenteral urea. Acta neurochir. (Wien), 10, 466-472.

Lundberg, N. (1960). Continuous recording and control of ventricular fluid pressure in neurosurgical practice. Acta psychiat. scand., 36, suppl. 149.

Ryder, H. W., Espey, F. F., Kristoff, F. V., and Evans, J. P. (1951) Observations on the interrelationships of intracranial pressure and cerebral blood flow. J. Neurosurg., 8, 46-58. 